Invited Lecture For Proceedings, Fourth European Symposium on Radiopharmacy and Radiopharmaceuticals, Zurich, Switzerland, May 1-4, 1991.

The Development of New Radionuclide Generator Systems for Nuclear Medicine Applications

F. F. Knapp, Jr., ${ }^{1 *}$ A. P. Callahan, ${ }^{1}$ S. Mirzadeh, ${ }^{1}$ C. Brihaye, ${ }^{2}$ and M. Guillaume ${ }^{2}$

${ }^{1}$ Nuclear Medicine Group Health and Safety Research Division

Oak Ridge National Laboratory Oak Ridge, Tennessee 37831-6022

and

${ }^{2}$ Cyclotron Research Center

University of Liège

Liège, Belgium

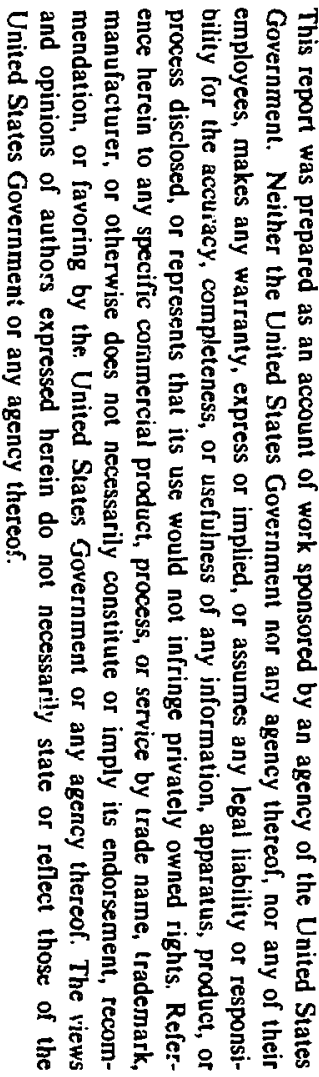

- To whom correspondence should be addressed

Research supported at ORNL by the Office of Health and Environmental Research, U.S. Department of Energy, under contract DE-AC05-84OR21400 with Martin Marietta Energy Systems, Inc.

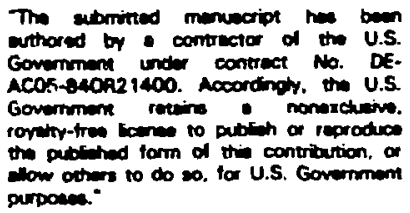




\title{
THE DEVELOPMENT OF NEW RADIONUCLIDE GENERATOR SYSTEMS FOR NUCLEAR MEDICINE APPLICATIONS
}

\author{
F. F. Knapp, Jr., ${ }^{1}$, A P. Callahan, ${ }^{1}$ S. Mirzadeh, ${ }^{1}$ C. Brihaye, ${ }^{2}$ and M. Guillaume ${ }^{2}$ \\ ${ }^{1}$ Nuclear Medicine Group \\ Health and Safety Research Division \\ Oak Ridge National Laboratory (ORNL) \\ Oak Ridge, Tennessee 37831-6022 \\ and \\ ${ }^{2}$ Cyclotron Research Center \\ University of Liège \\ Liège, Belgium
}

\begin{abstract}
Radioisotope generator systems have traditionally played a central role in nuclear medicine in providing radioisotopes for both research and clinical applications. A resurgence of interest in generator development has been stimulated by advances in antibody technology, instrumentation development, and positron emission tomography (PET). Complementary advances in the development of new chelating agents and radiolabeling techniques for attachment of radioisotopes to various tissue-specific agents have given further impetus to generator research. Widespread interest in the use of antibodies for the radioimmunodetection and therapy of cancer requires readily available sources of radioisotopes with the optimal properties. In this paper, the development of several tungsten-188/rhenium-188 prototype generators which provide rhenium-188 for radioimmunotherapy (RAIT) is discussed. We have recently demonstrated that carrier-free iridium-194 can be obtained from the activated carbon system from decay of reactor-produced osmium-194 for potential RAIT applications. Instrumentation advances such as the new generation of high-count-rate ("fast") gamma camera systems for first-pass technology require the availability of generator-produced ultra short-lived radicisotopes for radionuclide angiography (RNA). The activated carbon generator is an efficient system to obtain ultra short-lived iridium-191m from osmium-191 for RNA. In addition, the growing number of PET centers has stimulated research in generators which provide positron-emitting radioisotopes. Copper-62, obtained from the zinc-62 generator, is currently used for PET evaluation of organ perfusion. The availability of the parent radioisotopes, the fabrication and use of these generators, and the practical factors for use of these systems in the radiopharmacy are discussed.
\end{abstract}




\section{Introduction}

Our goal in this chapter is to review the current interest in radjonuclide generators and briefly discuss examples of systems currently under development. Examples of several generator systems currently under investigation at ORNL are discussed. The list of radionuclide generator systems summarized in Tables 1-3 include key examples of generator systems for which there is widespread interest. Several of these have been shown to be useful for clinical nuclear medicine applications. A number of earlier reviews have been published on radionuclide generator systems for nuclear medicine (examples include: Brucer, 1965; IAEA Meeting, 1970; Finn et al., 1983; Knapp and Butler, 1983; Lambrecht, 1984: Lebowitz and Richards, 1984; Guillaume and Brihaye, 1986 and 1987; Yano, 1987; and Volkert et al., 1991).

The use of short-lived radionuclides from generator systems (Table 1) for RNA stimulated widespread interest in the early 1980's (Proceedings of Single-Photon Ultrashort-Lived Radionuclides, 1985). Several prototype mercury-195m/gold-195m (Hg-195m/Au-195m) generator systems were available which provided $\mathrm{Au}-195 \mathrm{~m}$ and multi-center clinical trials were underway using Au-195m from the system developed by Byk-Mallinckrodt, Inc., which consisted of a silica gel adsorbent coated with zinc sulfide eluted with sodium thiosulfate (Panek et al., 1984). Although the use of Au-195m has not been reported for sometime, clinical applications of the ultra short-lived iridium-191m (4.9 s) available from several osmium-191/iridium-191m (Os-191/Ir-191m) prototype systems have been encouraging (Brihaye et al., 1986a and 1986b; Franken et al., 1989 and 1991; Packard et al., 1987; Hellman et al., 1989; Issachar et al., 1989). Although the $9.31 \mathrm{~min}$ half-life of tantalum-178 does not fall within the 1 minute limit which we define for an "ultra short-lived" daughter radioisotope, we include a description of the tungsteii-178/tantalum-178 (W-178/Ta-178) generator system in this discussion: since several papers have recently appeared which describe both the development and use of this system to provide Ta-178 for F.NA studies (Lacy, et al., 1988a and $1988 \mathrm{~b}$ ). Tantalum-178 from the W-178/Ta-178 system continues to be used, since it is specifically mated to the multi-wire camera system (Lacy et al., 1988a; Lacy et al., 1990).

With widespread interest in hospital-based positron emission tomographic (PET) systems, the availability of generator-derived positron emitting radionuclides is very important (Table 2). Because of the opportunity to perform PET evaluation of myocardial perfusion without the need of a hospital-based cyclotron for production of $\mathrm{O}$-15-water or N-13-ammonia , the strontium-82/rubidium-82 ( $\mathrm{Sr}-82 / \mathrm{Rb}-82$ ) system has received the greatest atterition (Schelbert et al., 1987). Naturally, those radionuclides which can be evaluated by direct intravenous administration are much easier to use and do not require any special chemical manipulations. In fact, the availability of the $\mathrm{Sr}-82 / \mathrm{Rb}-82$ system has been a major impetus for several hospitals to install PET systems both in the U.S. and in western Europe (Gould et al., 1989). The routine, dependable availability of $\mathrm{Sr}-82$ is an important issue. Because the two U.S. production sites at the Los Alamos National Laboratory (LANL) and the Brookhaven National Laboratory (BNL) are "parasitic" and dependent on the seasonal operation of large accelerators devoted to high physics research, the construction of a facility dedicated to the production of medical radioisotopes has been discussed (Tilyou et al., 1990a).

Although copper(II) complexes of various bis-thiosemicarbazones have been known for many years, only recently has this type of copper complex been exploited for use in nuclear medicine using the short-lived $(9.73 \mathrm{~min})$ copper -62 radionuclide, which is available from a zinc-62/copper-62 (Zn-62/Cu-62) generator system (Robinson et al., 1976 and 1980). The copper-62-pyruvaldehyde thiosemicarbazone (PTSM) complex or similar complexes are of 
interest for evaluation of regional organ perfusion with PET, particularly for the brain and heart (Green et al., 1990). Since the cyclotron-produced $\mathrm{Zn}-62$ parent has a half-jife of only $9.26 \mathrm{~h}$, it will remain to be seen how practical this generator system will be for routine use, which may be only at centers which have the necessary cyclotron production facilities.

A third important class of radionuclide generators are those systems which provide a daughter radioisotope which cen be used for therapeutic applications (Table 3). Interest and further development of these systems has grown rapidly in the last few years as advances in the development and success of antibodies for the treatment of cancer has progressed (Tilyou, 1990b; Go'denberg et al., 1989a and 1989b). In addition, other applications, such as the treatment of arthritis of the large synovial joints by the intraarticular injection of small particles radiolabeled with radionuclides ("radionuclide synovectomy"), have prompted research in this area (for example, see Sledge et al., 1986, for dysprosium-165; Spooren et al., 1985, for yttrium-90; Venkatersan et al., 1990, for thenium-188). Although much work has been focussed on the use of yttrium-90, available from the strontium-90/yttrium-90 (Sr-90/Y90) generator (Order et al., 1986), the potential danger from handling both the parent and daughter are quite great since both of these radioisotopes localize in bone with subsequent myelotoxicity (Sharkey et al., 1988; Anderson-Berg et al., 1987). Because of these dosimetry and health physics considerations, few institutions are evidently willing to have a large-scale Sr-90/Y-90 generator system in their radiopharmacy for routine use, although the fabrication of a convenient system for use in the radiopharmacy has been described (Chinol et al., 1987). The potential release of Y-90 from therapeutic agents in vivo can have the same fate of myelotoxicity. Another disadvantage of this system is the absence of gamma cmissions in the decay scheme of Y-90, which does not readily allow the use of a gamma camera to determine the biodistribution, estimate adsorbed dose, elc.

\section{Ultra Short-Lived Radioisotopes From Generators for First-Pass Studies}

Ultra short-lived radionuclides $\left(\mathrm{t}_{1 / 2}<1 \mathrm{~min}\right)$ available from radionuclide generator systems offer a readily available source of radioisotopes for the evaluation of ventricular function (left ventricular ejection fraction, $L V E F$ ) and regional wall motion by first pass radionuclide angiographic (RNA) techniques. The list of potential candidates is quite limired (Table 1), however, and this brief discussion is limited to several recent prototype generators which provide $\mathrm{Ir}-191 \mathrm{~m}$ from decay of Os-191. The obvious advantages in using generator-produced ultra short-lived radioisotopes include the unique opportunity to perform rapid, repeat studies and a greatly reduced radiation burden to both personnel and patients. Since the time required for vascuiar recirculation $(-25-30 \mathrm{~s})$ is much longer than the radioisotope physical half-life, very short-lived radioisotopes such as Ir-191m $\left(t_{12}=4.9 \mathrm{~s}\right)$ can thus be used to perform repeated RNA in different views or at increasing work load levels (Franken et al., 1989 and 1991). The completion of repeat RNA studies within a short time period is not possible, for instance, with technetium-99m labeled red blood cells for RNA. The tremendously reduced radiation dose (whole body $=2 \mathrm{mrad}$ ) with a single $100 \mathrm{mCi}$ bolus of Ir-191m compared with the dose (whole body $=150 \mathrm{mrad}$ ) used in a typical study $(10 \mathrm{mCi})$ 
with Tc-99m illustrates the important reduction in radiation exposure (Brihaye et al., 1986b).

Krypton $-81 \mathrm{~m}(\mathrm{Kr}-81 \mathrm{~m})$ can be adminisiered either intravenously (pulmonary perfusion) or by inhalation (pulmonary ventilation). The generator is available in Europe from the Cyclotron Research Centre in Liege, Belgium, and is primarily used for perfusion studies. Since krypton gas is expired from the lungs, use of $\mathrm{Kr}-81 \mathrm{~m}$ in cardiology by non-invasive techniques is thus limited to studies of the right heart chambers.

The use of ultra short-lived radioisotopes from generator systems for cardiology studies witnessed a surge of attention during the late 1970's and early 1980's, which was probably primarily driven by industrial interest in development of the mercury-195/gold-195m (Hg-195/Au-195m) generator system (Figure 1). This was the first opportunity for clinical investigators to have an ultra short-lived radioisotope available for evaluation in comparison with other methodologies for the determination of ventricular performance and wall motion. The impact a major radiopharmaceutical manufacturer can have on the promotion of a new technology when new agents are made available for multi-center trials is very crucial. When the $\mathrm{Hg}-195 / \mathrm{Au}-195 \mathrm{~m}$ system was no longer available from Byk-Mallinckrodt, Inc., interest rapidly declined. As an example (Figure 1), the number of papers describing the use of Au-195m presented at the annual meetings of the Society of Nuclear Medicine (SNM), rapidly declined to zero after the early enthusiasm and support for clinical trials by BykMallinchrodt.

\section{THE OSMIUM-191/IRIDIUM-191 GENERATOR SYSTEM}

Because of the very short 4.96 second half-life of the $\mathrm{Ir}-191 \mathrm{~m}$ daughter, the Os-191/Ir-191m generators have several special requirements in comparison to generators which provide daughter radioisotopes with much longer half-lives. Very high elution flow rates $(>100$ $\mathrm{ml} / \mathrm{min}$ ) are required to minimize losses in yields during transit into the venous line prior to initiation of the RNA acquisition, hence column resistance must be minimized, which precludes the use of small particles for maximum surface area. In our experience, development thus requires an empirical evaluation of the best particle size for the adsorbent to compromise maximal flow rates and maximal surface area (Brihaye, et al., 1986a). Although the various prototypes all report good yields of $\mathrm{Ir}-191 \mathrm{~m}$, the absolute yield values should probably be accepted with caution because of the inherent difficulties and uncertainties in quantitating the levels of activity with such a rapidly decaying radionuclide (Brihaye, et al., 1986b).

More recently, interest in the advantages of using ultra short-lived Ir-191m for RNA has stimulated the development of several prototype Os-191/Ir-191m generator systems (Table 4). These generators are prepared using Os-191 produced by neutron irradiation of enriched Os-190 targets (Figure 2). The production of Os-191 and accompanying impurities has been studied in some detail (Brihaye et al., 1989; Butler et al., 1982 and 1986). Our recent distillation method for removal of osmium from iridium as osmium tetroxide provides an improved technique for removal of the significant levels of Ir-192 produced by the longer irradiation periods required for the production of high specific activity Os-191 in lower flux 
reactors (Brihaye, et al., 1989;. Prototypes currently in clinical use include the activated carbon system developed in collaboration between our Nuclear Medicine Group at the Oak Ridge National Laboratory and the Cyclotron Research Center at the University of Liège, Belgium (Brihaye, et al., 1986a, 1986b, 1986c, and 1987), which involves the adsorption of an Os(IV) species on specially treated heat-activated charcoal eluted with $\mathrm{pH} 2$ saline containing $0.025 \%$ sodium iodide. In addition, the group at Children's Hospital in Boston has reported the use of Os(VI) species on AGMP-1 eluted with oxalate (Packard et al., 1987), and a group in Soreq, Israel has evaluated the use of Os(VI) bound to silica gel impregnated with tridodecylmethylammonium chloride (SG-TDMAC) (Issacher, et al., 1989 and Hellman, et al., 1989).

The Soreq Os-191/Ir-191m generator prototype utilizes Os(VI) as osmyl chloride prepared by dissolution of reactor-produced Os-191 in 5\% sodium hypochlorite solution. The osmyl chloride is adsorbed on the SG-TDMAC slurried in a glass column with $\mathrm{pH} 1$ saline. Equilibration of the generator at room temperature for 24 hours before elution is evidently important to insure the expected generator performance. The generator is eluted with $\mathrm{pH} 1$ saline $/ \mathrm{HCl}$ with the final eluate buffered with $1 \mathrm{M}$ succinate solution ( $\mathrm{pH} \mathrm{9)}$. Because of relatively high parent breakthrough from the SG-TDMAC column, a post-elution activated carbon "scavenger" column (prior to buffer addition) is required for reduction of the parent breakthrough to acceptable levels (1-10 x 10 $\left.0^{-4} \%\right)$. A 0.22 micron Millipore filter is attached at the end of the elution line prior to intravenous administration. The reported yields of Ir-191m are $21-33 \%$ of the equilibrium values. This generator has been used to provide Ir-191 $\mathrm{m}$ for the evaluation of ventricular ejection fraction in a series of patients (Hellman, et al., 1989).

While the ORNL/Liège and the Soreq Os-191//r-191m generators were primarily developed to provide Ir-191 m for evaluation of ventricular performance in adults, a group at Children's Hospital in Boston has focussed on the use of $\mathrm{Ir}-191 \mathrm{~m}$ for evaluation of intracardiac shunts in neonates and infants, an application which requires very small bolus volumes. The lasest prototype from this group (Packard et al., 1987) involves initial ethanol reduction of potassium perosmate (Os-VIII), prepared from the reactor-produced Os-191 metal, to potassium osmate (Os-VI). Treatment of the osmate in $0.1 \mathrm{~N} \mathrm{KOH}$ solution with an excess of oxalic acid then provides the potassium trans-dioxobisoxalatoosmtae (VI) complex which is adsorbed on the AG MP-1 anion exchange resin, previously converted to the oxalate form. The generator does not require a "scavenger" column and is eluted with $\mathrm{pH} 10.9 \%$ saline solution. This system provides good yields of $\mathrm{Ir}-191 \mathrm{~m}(10 \% / \mathrm{ml})$ with low associated Os-191 breakthrough $\left(3 \times 10^{-4} \%\right)$ and no toxicity detected with intravenous administration of the oxalate solution into animals. This system is currently being used for angiocardiography in children.

Our activated carbon system has been used for the evaluation of left ventricular ejection fraction and regional wall motion studies in over 600 patient studies at the Niuclear Medicine Department at Middelheim Hospital in Antwerp, Belgium (Franken et al., 1989 and 1991) and for cardiac studies and evaluation of arterial transit at the University of Liege, Belgium (Guillaume et al., 1988). Currently, RNA studies are alsc being conducted at the Clinic for 
Nuclear Medicine at the University of Bonn, Germany (J. Kropp, M. D. and H.-J. Biersack, M.D.; Reske, et al., 1986), and patient studies have also been initiated in Finland under a collaborative program coordinated by the VTT Technology Oy/Inc. at the VTT Reactor Laboratory in Espoo (Kariemo, et al., 1990).

One of the key requirements for the use and intercomparison of repeat studies is the reproducibility of the elution with subsequent injection of the Ir-191m bolus. Our current activated carbon prototype system, this typically involves rapid elution of $2.5 \mathrm{ml}$ of the pH 2 saline eluant through the generator (Brihaye et al., 1986b). Because of this rather high acidity, subsequent neutralization is required which is accomplished by the concomitant mixing with $0.13 \mathrm{M}$ TRIS buffer during elution. The neutralized bolus is then stored for the shoitest period of time in a length of shielded extension tubing prior to manual flushing with physiological saline into a line previously placed in the antecubital or jugular vein. Manually, this process can be conducted in less than 2 seconds on an average but the elution time obviously varies from bolus to bolus and also idepends on the person eluting the generator. It is also important to minimize the accumalative exposure to personal resulting from multiple injections.

For these reasons a micro-processor-controlled automated elution system has been developed at the University of Liege to ensure minimal differences in elution time and integrity between boluses. This system consists of a motor-driven device which compresses the elution and neutralization syringe plungers simultaneously and also automatically refills the syringes from reservoirs. Either the total volume or elution rate can be controlled with convenient thumb screw adjustments. Using this automated system, the bolus can be administered reproducibly in less than 1.5 seconds.

One of the issues which will promote continued interest in the use of Ir-191m will undoubtedly be the successful development and availability of cost-effective camera systems with high count rate capabilities. Examples irclude the multi-wire proportional counter camera (RCPC) systems (Lacy et al., 1988a and 1988b) and high count-rate gamma cameras using crystal detectors. While these systems have very high count rate capabilities and high spacial resolution, their use has been very limited, and no major manufacturer has evidently yet undertaken the development of such a system.

\section{THE TUNGSTEN-178/TANTALUM-178 GENERATOR SYSTEM}

One example of a new high count-rate system especially designed for RNA is the system available from Xenos, Inc., which was developed in conjunction with the tungsten-178/tantalum-178 (W-178/Ta-178) generator system (Table 1). Multi-wire gas counting (MWGC) systems employing xenon gas at low pressure are perfectly suited for use with Ta-178 because of the emission of X-rays with energy of $55-65 \mathrm{keV}\left(\mathrm{K}_{\alpha}=55 \mathrm{keV}, 67.4 \% ; \mathrm{K}_{\mathrm{g}}=64 \mathrm{keV}\right.$, $17.7 \%)$ which is suitable for excitation of the xenon $\left(\mathrm{K}_{\alpha}\right.$ edge of xenon is at $\left.30 \mathrm{keV}\right)$. These imaging systems are best used with low energy emitters and have very high intrinsir. resolution and high count-rate capability. The generator, which is now used to provide Ta-178 for cardiac studies, is prepared by adsorption of the weakly acidic $0.1 \mathrm{~N} \mathrm{HCl}$ solution of the 
Ta-178 (Figure 3) from the processed target (containing $0.1 \% \mathrm{H}_{2} \mathrm{O}_{2}$ ) to a Dowex AG 1-X8 anion exchange column in the chloride form (Lacy, et al., 1988a). The column is then immediately flushed with several column volumes of $0.03 \mathrm{~N} \mathrm{HCl}$ containing $0.1 \% \mathrm{H}_{2} \mathrm{O}_{2}$ and is ready for use. A careful systematic study determined that an $\mathrm{HCl}$ concentration of $0.03 \mathrm{~N}$ was best as a compromise in assuring a significant increase in the total elution capacity of the generator with the sacrifice of only a small increase in the parent breakthrough. The sterile column is prepared by washing with dilute $\mathrm{HCl} / \mathrm{H}_{2} \mathrm{O}_{2}$ solutions. Rapid elution of Ta-178 from the generator is accomplished with a buffer solution of sodium diphosphate which neutralizes the eluant to $\mathrm{pH} 7$ ready for use. An important and interesting observation which has provided a means of increasing the elution yields of Ta-178 is elution at $4^{\circ} \mathrm{C}(57 \%$ yield) compared to $24^{\circ} \mathrm{C}$ ( $28 \%$ yield). Over a useful shelf-life of, for example 60 days, the yield averages $45-55 \%$ with a concomitant $W-178$ breakthrough of about $1.0-1.5 \times 10^{-3} \%$.

Until more developmental studies are performed and the obvious advantages for use of shortlived radioisotopes from generator systems are clearly illustrated in comparison to other modalities, and until nuclear cardiologists and nuclear medicine physicians offer and/or request such studies, RNA with ultra short-lived radioisotopes from these generator systems will not become routine.

\section{Radioisotopes from Generators for Therapeutic Applications}

\section{THE TUNGSTEN-188/RHENIUM-188 GENERATOR SYSTEM}

There is an important advantage in the use of therapeutic radionuclides which also emit gamma photons suitable for imaging, since this dual-role with a single prenaration and administration would overcome the cumbersome and time consuming expense of using two different radionuclides, such as indium-111 for imaging and yttrium-90 for therapy. In addition, there are obvious possible errors introduced when the results of two completely different radiolabeling methods are compared because of differences in immunoreactivity, etc. Rhenium-188 ( $R e-188)\left(t_{1,2} 16.9 \mathrm{~h}\right)$ is a potentially important generator-produced radioisotope which decays by emission of a high energy $B^{*}\left(E_{a v}=764 \mathrm{keV}\right)$ and a gamma photon (155 keV, $15 \%$ ) and is formed by $B^{-}$decay of tungsten-188 (W-188) (Figure 4). Tungsten-188 is reactorproduced by double neutron capture of enriched tungsten-186. In fact, use of Re-188 from a W-188/Re-188 zirconium oxide generator (Lewis et al., 1966) was proposed as early as 1965 as an alternative to $\mathrm{Tc}-99 \mathrm{~m}$ for diagnostic applications, and the rapid excretion of perrhenate via the urinary bladder in human volunteers was demonstrated (Hayes et al., 19055 and 1966). Until a resurgence in interest in radionuclides for RATT in the mid 1980's, further interest in this generator was not pursued. Our interest was rekindled because of the possibility of radiolabeling monoclos:al antibodies (MoAbs) with $\mathrm{Re}-188$. We have thus reinvestigated the reactor production of W-188 and the fabrication of both zirconium oxide based and aluminum oxide W-188/Re-188 generator systems (Callahan et al., 1987 and 1989). Although Re-188 perrhenic acid can be eluted from the zirconium oxide system with methylethylketone (MEK), we have not pursued this approach further because of the apparent advantages of alumina and an aqueous eluant since the $\mathrm{Al}_{2} \mathrm{O}_{3}$ system eluted with physiological saline readily provides 
reproducible yields ( $75-85 \%$ ) of $\mathrm{Re}-188$ as sodium perrhenate (Callahan et al., 1989; Coursey et al., 1990).

A variety of techniques are available for attaching $\mathrm{Re}-188$ to antibodies including both "indirect" and "direct" techniques, however, a detailed discussion of these methods is beyond the scope of this presentation. The bifunctional chelate methods (indirect) previously developed for attachment of Re-186 to antibodies, such as the $\mathrm{N}_{2} \mathrm{~S}_{2}$ ligand with a five-carbon spacer by NeoRex, Inc. (Fritzberg et al., 1987), would be expected to work just as well with Re-188. An advantage of Re-188 is that it can be obtained carrier-free from the W-188/Re-188 generator system. Another very promising approach is the direct method for attachment of Re-188 to antibodies involving the reduction of perrhenate in the presence of "pretinned" or thiol-reduced antibody in which disulfide bonds have been reduced. This method has been widely explored for radiolabeling with Tc-99m (for example, see Mather et al., 1990 and Eckelman, et al., 1991) and has the advantages that it is very simple and can be readily adapted to a instant "kit" form. This direct Jabeling approach evidently works well with the IgG class of immunoglobulins, which are rich in -S-S- intramolecular bonds. More recentiy, initial studies with $\mathrm{Re}-188$ have provided antibodies which retain their immunoreactivity and show good tumor uptake and tumor/organ ratios in tumor-implanted nude mice (Griffiths, et al., 1991a and 1991b).

The W-188/Re-188 generator system developed by the group at the Missouri University Research Reactor (MURR) in conjunction with Neorex, Inc. (Seattle, Washington) is a unique system specifically designed for use with low specific activity tungsten-188 (Ehrhardt, et al., 1987 and 1990). Rather than using the "chromatographic" generator concept where the parent radioisotope is adsorbed on the top layers of support material, the MURR system uses a zirconium oxide "gel" system prepared by combining the processed sodium tungstate with zirconyl nitrate in acid solution with careful $\mathrm{pH}$ control to precipitate zirconyl tungstate. The precipitate is washed successively with water and organic solvents and air dried to form a freeflowing powder which is then packed in the generator columns. Elution of the generator with normal saline provides the sodium perrhenate daughter in yields of $50-70 \%$, based on the levels of Re-188 available from decay of the W-188. Analysis by HPLC demonstrates that the Re-188 eluate is $>99 \%$ perrhenate. Clinical "prototype" generators as large as $225 \mathrm{mCi}$ have been evaluated and yields are consistently high for several months. Breakthrough values for the W-188 parent are about $1 \mathrm{ppm}$ per bolus (e.g., approximately 10 $0^{-4} \%$ ), which is comparable to W-188 breakthrough from the ORNL aluminum oxide system (vide infra). The advantages of this system are the use of very low specific activity W-188 and the elution of relatively small bolus volumes of sodium perrhenate of about $3 \mathrm{ml}$.

Investigators in the U.S.S.R. have also recently described the preparation and evaluation of an alumina-based W-188/Re-188 generator system (Kodina, et al., 1990). These investigators have reported the systematic evaluation of W-188 (W-187) sorption on alumina from several acidic aqueous phases and sodium sulfate, sodium chloride and sodium nitrate. Alumina was identified as the best adsorbent with best stability in a pH range of 1-6. While $0.15 \mathrm{M}$ saline was the eluant of choice, sodium sulfate in concentrations less than 0.035 molar also eluted perrhenate in good yields. Maximal yields for elution of perrhenate with saline were $70.90 \%$ 
of Re-188 based on elution every three days, depending upon the elution volume. e.g., about $60-70 \%$ was eluted in $3 \mathrm{ml}$ and $85-90 \%$ in $7-8 \mathrm{ml}$. The gencrators exhibited reproducible performance over a 6-12 month period, although no values of W-188 parent breakthrough were reported.

We have more recently further developed our ORNL alumina prototype to include post elution ion exchange columns to provide the Re-188 as perrhenic acid. In addition, we have shown that post-elution through commercially available alumina SepPaks is an effective and convenient way to remove and quantitate the low levels of W-188 parent breakthrough in "real time". In W-188/Re-188 equilibrium mixtures or in mixtures which contain as high as $0.1 \% \mathrm{~W}-188$, the gamma photons emitted from decay of the W-188 parent cannot be detected by gamma spectroscopy. The post elution alumina "scavenger", however, traps the W-188 breakthrough and, following thorough washing to remove most of the Re-188 the SepPak can be counted directly in a gamma spectrometer with the 227 and $290 \mathrm{KeV}$ photons clearly detected. The use of either cation and anion exchange columns provides Re-188 in the form of perrhenic acid, which may be useful for radiolabeling applications (Lisic et al., 1991).

Our experience to this date has involved generators loaded with only low levels $(<10 \mathrm{mCi})$ of the W-188 parent. The ORNL High Flux Isotope Reactor (HFIR) has the optimal high neutron flux of about $2 \times 10^{15}$ neutrons $/ \mathrm{cm}^{2} \mathrm{sec}$ required for production of $W /-188$, and was shut down from November 1986 through July 1990. Alternative production stes such as the Missouri University Research Reactor (MURR) have a much lower neutron fluence and thus a lower production capacity. Because of the importance of being able to use reactors with lower neutron flux, we pursued the development of a generator that could easily use low specific activity W-188. As the specific activity of the W-188 as potassium tungstate decreases, the amount of alumina column support required increases, which requires a much larger volume of saline eluent, significantly diluting the specific volume $(\mathrm{mCi} / \mathrm{ml})$ of the eluant. Since MoAbs are usually radiolabeled in very small $(<1 \mathrm{ml}$ ) volumes because of bimolecular kinetics, the eluant must be concentrated. This may often be impractical, since, as an example, evaporation of $50 \mathrm{ml}$ of a $0.9 \% \mathrm{NaCl}$ solution would result in concentration of $450 \mathrm{mg}$ of $\mathrm{NaCl}$ into a very small volume. Since Re-188 cannot be eluted from the generator with water, removal of the large amounts of Na cations is necessary to provide a solution which can be concentrated. For this reason, we have recently developed a "tandem" system which utilizes ion exchange columns distal to the generator for removal of the cations. In this way, solutions of carrier-free Re-188 perrhenic acid are readily concentrated by evaporation or lyophilization to the concentrated solutions of $\mathrm{Re}-188$ required for MoAb radiolabeling.

\section{THE OSMIUM-194/IRIDIUM-194 GENERATOR SYSTEM}

Iridium-194 (Table 3) is another interesting RAIT candidate that is available from a radionuclide generator. We have evaluated the osmium-194/-iridium-194 (Os-194/Ir-194) generator for the first time as a source of Ir-194 for evaluation for RAIT (Mirzadeh et al., 1991). Osmium-194 ( $\left.t_{12} 6 \mathrm{y}\right)$ is reactor-produced (Figure 5) by double neutron capture of osmium-192 and decays by $B^{-}$-decay to iridium-194 $\left(t_{1 / 2}=19 \mathrm{~h}\right)$. Iridium-194 is of interest for 
RAIT since it decays with the emission of high energy $B^{-}\left(E_{2 v}=790 \mathrm{keV}\right)$ and also a gamma photon ( $319 \mathrm{keV}$ ) which is suitable for imaging. Similar to Re-188, the emission of a photon would allow biodistribution and dosimetry studies with Ir-194.

Our experience with osmium chemistry and the activated carbon-based generator system developed for separation of $\mathrm{Ir}-191 \mathrm{~m}$ from Os-191 (vide ante) provided the impetus for the development of our first prototype for separation of Ir-194 from Os-194. The acid-base equilibrium of $\mathrm{Os}$ (VIII) as $\mathrm{OsO}_{4}\left(\mathrm{H}^{+}\right.$, gas) $/ \mathrm{K}_{2} \mathrm{Os}(\mathrm{OH})_{2} \mathrm{O}_{4}(\mathrm{OH}$; solution) provides a simple method for purification of osmium radioisotopes. The reactor-produced metallic Os-194 is converted to $\mathrm{OsO}_{4}$, for example, by treatment with molecular oxygen in a tube furnace, and trapped in $\mathrm{KOH}$ as $\mathrm{K}_{2} \mathrm{Os}(\mathrm{OH})_{2} \mathrm{O}_{4}$. Subsequent sequential reduction with $\mathrm{HCl}$ and ethanol as described in detail earlier (Brihaye et al., 1986 and 1987) provides $\mathrm{K}_{2} \mathrm{OsCl}_{6}$ (Os-IV) which is loaded onto specially heat-treated coconut charcoal (Brihaye et al., 1986). Elution with pH 2 saline provides carrier-free Ir-194 in reproducible $75-85 \%$ yields with low Os-194 breakthrough (Mirzadeh et al., 1991).

If the performance of the generator system is unchanged, the usual shelf-life of this system could be for at least one half-life, which is about 3 years. Although it would traditionally be unusual to expect to use a generator system for such an extended period, there are similar systems, such as the Ge-68/Ga-68, where the Ge-68 parent has a 271 day half-life. Factors other than performance (e.g., breakthrough and yield) which determine the useful life include sterility and pyrogenicity. For such a long-lived parent, one would thus institute a system where, for instance, samples are taken at the end of the week for sterility and pyrogenicity testing, so that the generator can then be approved for use the next week. The current stages of this project involve an evaluation of nitrogen and other heteroatom multidentate ligands for attachment of this interesting therapeutic radionuclide to antibodies and other therapeutic agents.

\section{Radioisotopes from Generators for Positron Emission Tomography (PET)}

\section{THE ZINC-62/COPPER-62 RADIONUCLDIE GENERATOR SYSTEM}

Because of the importance of obtaining quantitative information from diagnostic nuclear medicine imaging procedures, the widespread use of positron-emitting radionuclide for positron emission tomography (PET) will undoubtedly be, at least in part, dependent upon the availability of generators which will provide radiojsotopes in a cost-effective manner. It is not yet clear if these generators can be provided in a manner which is cost-effective with the levels of funds which will be reimbursable from third parties in an era where costcontainment is a major factor. As with other generator-produced radionuclides for RNA and RAIT, there are a limited number of candidates available for PET (Table 3). Rubidium-82 has been evaiuated for nearly a decade as a myocardial perfusion agent, and a commercial system is now available from Squibb Diagnostics (Gennaro et al., 1984; Gould et al., 1986). While research with gallium- 68 from the Ge-68/Ga-68 has continued, there has not been 
widespread use of this radionuclide, piobably because effective, simple methods for attachment of Ga-68 to various tissue-specific agents have not yet been optimized.

The "new" system which has recently received the most attention is the zinc-62/copper-62 (Zn-62/Cu-62) generator. Cyclotron-produced (Figure 6) $\mathrm{Zn}-62\left(\mathrm{t}_{1 / 2} 9.2 \mathrm{~h}\right.$ ) (Ramamoorthy et al., 1981; Riley et al., 1981; Robinson et al., 1976 and 1980; Thakur et al., 1969; Nierinckx, 1977; Yano et al., 1977) decays to $\mathrm{Cu}-62\left(\mathrm{t}_{12} 9.73 \mathrm{~min}\right)$ which decays by positron emission ( $\boldsymbol{B}^{+}$ 97.8\%). For many years chemists have used the well-known strong binding of $\mathrm{Cu}^{++}$to sulfur as a means of preparing cupric ion chelating groups. As with many generator-derived radionuclides, their usefulness is entirely dependent upon the availability of a tissue-specific agent to which they can be attached and the availability of instrumentation and important applications. The binding of copper to pyruvaldehyde bis-semithiocarbazone (PTSM) is wellknown and, in fact, anti-tumor activity of this agent was established several years ago (Minke] et al., 1978; Petering et al., 1980).

The high level (>300 $\mathrm{mCi}$ ) $\mathrm{Zn}-62 / \mathrm{Cu}-62$ generators now being used for patient studies are prepared by loading a $2 \mathrm{~N} \mathrm{HCl}$ solution of the cyclotron-produced $\mathrm{Zn}-62$ target material on a Dowex $1 \times 8$ ion exchange column in the chloride form. The column is eluted with $2 \mathrm{~N} \mathrm{HCl}$ (Green, et al., 1987 and 1990). This processing and generator fabrication process is essentially the same as for low-level generators described earlier by Robinson, et al. (1980). The $2 \mathrm{~N} \mathrm{HCl}$ eluant containing the $\mathrm{Cu}-62$ is subsequently buffered with $3 \mathrm{~N}$ sodium acetate and then rapidly complexed with the PTSM ligand in ethanol solution and passed through a SepPak ${ }^{3}$ which is washed with ethanol. The Cu-PTSM product is then diluted with saline and passed through a Millipore filter for sterilization prior to intravenous administration. The complete synthesis, purification and formulation procedure can be completed in 4.5-6 minutes with a final yield of about $50 \%$. Since the synthesis of Cu-62-PTSM is simple with rapid reaction of Cu-62(II) with the ligand in good yield, evaluation of the broad use of this interesting agent for evaluation of organ perfusion by PET is being pursued. Perfusion studies of the heart and brain of various animal species (Green, et al., 1990), kidneys of dogs (Barnhart et al., 1990) and colorectal carcinoma tumors in Syrian hamsters (Mathias et al., 1990) have already been reported.

The Cu-62 PTSM has provided a useful blood flow agent for PET (Green et al., 1988, 1989, and 1990). More recently, the first comparative cerebral flow studies with Cu-62-PTSM and O-15-water have been reported in humans and good agreement between these two agents has been demonstrated (Green et al., 1990). The potential widespread use of this agent may be based upon its simple preparation, and the fact that $\mathrm{Zn}-62$ can be readily produced in medical cyclotrons (Robinson et al., 1980; Welch et al., 1986). The short half-life of the $\mathrm{Zn}-62$ parent coupled with the facilities and manpower required for processing and generator fabrication may, however, be beyond the capability of many PET centers. However, it may be that the concept of a "regional pharmacy" may be excellent for this generator system. if regulatory issues can be resolved. 


\section{Summary}

As the foregoing examples have demonstrated, the interest and subsequent development of several new radionuclide generator systems has been closely dependent upon developments in complimentary technologies. In many instances, such as for the development of generators which produce daughter radioisotopes for therapy, the rapid development of antibody preparation and targeting has been the driving force. Examples include development of "fast camera" systems, success in targeting antibodies to tumors, and of course, interest by cardiologists in the benefits of RNA and improved generator systems. In spite of these obvious advantages, the routine use of uitra short-lived radioisotopes from generators, for instance, has not yei gained widespread interest. The lack of the necessary commitment which would be required from a major radiopharmaceutical manufacturer is a major issue. In addition, the regulatory issues and the additional technical expertise required for the "first pass" technique compared with the "equilibrium" method and the more traditional mindset of residency training in cardiology and nuclear cardiology are additional factors.

\section{Acknowledgements}

Research at ORNL is supported by the Office of Health and Environmental Research, U.S. Department of Energy, under contract DE-AC05-84OR21400 with Martin Marjetta Energy Systems, Inc. The authors thank Linda Ailey for secretarial and editorial assistance during the preparation of this manuscript.

\section{References}

Anderson-Berg, W. T., Squire, R. A. and Strand, M. (1987) 'Specific Radioimmunotherapy using ${ }^{90}$ Y-Labeled Monoclonal Antibody in Erythroleukemic Mice,' Cancer Res. 47, $1905-1912$.

Barnhari, A. J., Voorhees, W. D. and Green, M. A. (1990) 'Correlation of Cu(PTSM) Localization with Regional Blood Flow in the Dog Kidney,' J. Nucl. Med. 31, 914 (abstract).

Brihaye, C., Butler, T. A, and Knapp, F. F., Jr. (1986a) The Os-191/Ir-191m Generator for Clinical Use. I. Evaluation of Potential Absorbents,' J. Radioanalyt. Chem. and Nucl. Chem., 102(2), 399-411.

Brihaye, C., Butler, T. A, Knapp, F. F., Jr., and Guillaume, M. (1986b) 'A New Osmium191//ridium-191m Radionuclide Generator System Using Activated Carbon.' J. Nucl. Med., 27, 380-387.

Brihaye C., Guillaume M., Butler T. A., and Knapp, F. F., Jr. (1986c) 'Evaluation of tine Reactor Production of Osmium-191 For Use in the Carbon-Based Os-191/1r-191m Medical Generator,' Seminar on Radionuclide Generators, Vienna, Austria, Oct. 1317, 1986. 
Brihaye C., Dewez S., Guillaume M., Callahan A. P., Rice D. E., and Knapp F. F., Jr. (1989) 'Reactor Production and Purification of Osmium-191 for Use in a New Osmium191/Iridium-191m Radionuclide Generator System,' Appl. Radiat. and Isotopes, 40, 183-191.

Brucer, M. (1965) 'Medical Cows,' Isotopes and Radiation Technology 3, 1-2.

Butler T. A, Guyer C. E., and Knapp F. F., Jr. (1982) 'Reactor Production of Osmium-191: Factors Important for Clinical Application of the Os-191/1r-191m Ultra Short-Lived Radionuclide Generator,' Proc. of the 3rd World Congress of Nuclear Medicine and Biology, Paris, France, Aug. 29-Sept. 2, 1982: 617-620.

Butler T. A., Guyer C. E., and Knapp F. F., Jr. (1986) 'Production of Osmium-191 in the Oak Ridge High Flux Isotope Reactor,' In, Proceedings, International Symposium on Single-Photon Ultra-Short Lived Radionuclides, U.S. Department of Energy, DOE Symposium Series 57, Office of Scientif. and Tech. Info., Oak Ridge, TN; pp 195-201; CONF-830504 (DE83017017).

Callahan, A. P., Rice, D. E. and Knapp, F. F., Jr. (1989) 'Rhenium-188 for Therapeutic Applications from an Alumina Based Tungsten-188/-Rhenium-188 Radionuclide Generator,' NucCompact - Eur./Amer. Commun. Nucl. Med. 20, 3-6.

Callahan, A. P., Rice, D. E. and Knapp, F. ᄃ., Jr. (1987) 'Availability of Rhenium-188 form a Tungsten-188/Rhenium-188 Generator System for Therapeutic Applications,' J. Nucl. Med. 28, 657 (abstract).

Chinol, M. and Hnatowich, D. J., (1987) 'Generator-Produced Yttrium-90 for Radioimmunotherapy,' J. Nucl. Med. 28, 1465-1470.

Coursey, B. M., Calhoun, J. M., Cessna, J., Hoppes, D. D., Schima, F. J., Untenweger, M. P., Golas, D. B., Callahan, A. P., Mirzadeh, S., and Knapp, F. F., Jr. (1990), 'Assay of the Eluent from the Alumina-Based Tungsten-188/Rhenium-188 Generator,' Radioactivity and Radiochemistry 3, 39-49.

Ehrhardt, G., Ketring, A. P., Turpin, T. A., Razavi, M.S., Vanderheyden, J.-L. and Fritzberg, A. R. (1987) 'An Improved Tungsten-188/Rhenium-188 Generator for Radiotherapeutic Applications', J. Nucl. Med. 28, 656-657.

Eckelman, W. C. and Steigman, J. (1991) 'Direct Labeling with Technetium-99m', Nucl. Med. Biol. 18, 3-7.

Ehrhardt, G., Ketring, A. P., Turpin, T. A., Razavi, M.S., Vanderheyden, J.-L., Fu, S.-M. and Fritzberg, A. R. (1990) 'A Convenient Tungsten-188/-Rhenium-188 Generator for Therapeutic Applications Using Low Specific Activity Tungsten-188', In, Technetium and Rhenium in Chemistry and Nuclear Medicine 3, M. Nicolini and G. Bandoli, editors, Corina International, 631-634.

Finn, R. D., Molinski, V. J., Hupf, H. B., and Kramer, H. (1983) 'Radionuclide Generators for Biomedical Applications,' In, Nuclear Sciences Series, Nuclear Medicine, United States Department of Energy, NAS-NS-3202 (DE83016360), 97-157.

Franken, P. R., Dobbeleir, A., Ham, H. R., Brihaye, C., Guillaume, M., Knapp, F. F., Jr., and Vandevivere, J. (1989) 'Ultrashort-Lived Iridium-191m from a New Carbon-Based Generator System for Left Ventricular First-Pass Angiocardiography,' J. Nucl. Med. 30, 1025-1031. 
Franken, P. R., Dobbeleir, A. A., Ham, H. R., Ranquin, R., Lieber, S., Van Den Branden, F., Van Den Heuvel, P., Brihaye, C., Guillaume, M., Knapp, F. F., Jr., and Vandevivere, J. (1991) (submitted) 'Discrepancy Between Myocardial Perfusion and Regional Wall Motion at Rest and During Exercise in Patients with Coronary Artery Disease,' J. Nucl. Med.

Fritzberg, A. R. (1987) 'Advances in ${ }^{99 \mathrm{~m}}$ Tc-Labeling of Antibodies,' Nukelarmedizin 26, 7-12. Garty, I. I., Serafini, A. N. and Sfakianakis, G. N. (1989) 'Radioimmuno-scintigraphy May Detect Early Cancer,' Diag. Imaging February, 83-92.

Gennaro, G. P., Neirinckx, R. D., Bergner, B., Muller, W. R., Waranis, A, Haney, T. A, Barker, S. L., Loberg, M. D. and Yarnais, A. (1984) 'A Radionuclide Generator and Infusion System for Pharmaceutical Quality Rubidium-82', In, Radionuclide Generators - New Systems for Nuclear Medicine Applications, F. F. Knapp, Jr. and T. A. Butler, editors, ACS Symposium Series, No. 242, ACS, Washington, D. C., pp.135-150.

Goldenberg, D. M. (1989a) 'Targeted Cancer Treatment,' Immunology Today, 10, 286-288.

Goldenberg, D. M. (1989b) 'Future Role of Radiolabeled Monoclonal Antibodies in Oncological Diagnosis and Therapy', Seminars in Nuclear Medicine, 19, 332-339.

Gould, K. L., Goldstein, R. A. and Mullani, N. A. (1989) 'Economic Analysis of Clinical Positron Emission Tomography of the Heart with Rubidium-82,' J. Nucl. Med. 30, 707-717.

Gould, K. L., Goldstein, R. A., Mullani, N. A. (1986) 'Non-Invasive Assessment of Coronary Stenoses by Myocardial Perfusion Imaging During Pharmacologic Coronary Vasodilation. VIII. Clinical Feasibility of Positron Cardiac imaging Without a Cyclotron Using Generator-Produced Rubidium-82,' J. Amer. Coll. Cardiol. 7, 775789.

Green, M. A. (1987) 'A Potential Copper Radicpharmaceutical for Imaging the Heart and Brain: Copper-Labelled Pyruvaldehyde Bis( $\mathrm{N}^{4}$-methylthiosemicarbazone), 'Nucl. Med. Biol. 14, 1- .

Green, M. A., and Klippenstein, D. L. (1988) 'Copper(II)Bis-(thiosemi-carbazone) Complexes as Potential Tracers for Evaluation of Cerebral and Myocardial Blood Flow with PET,' J. Nucl. Med., 29, 1549-1559.

Green, M. A., Mathias, C. J., Welch, M. J., McGuire, A. H., Perry, D., Fernandez-Rubio, F., Perlmutter, J. S., Raichle, M. E. and Bergmann, S. R. (1990) 'Copper-62-Labeled Pyruvaldehyde Bis( $\mathrm{N}^{4}$-methylthio-semicarbazonato)copper(II): Synthesis and Evaluation as a Positron Emission Tomography Tracer for Cerebral and Myocardial Perfusion,' J. Nucl. Med. 31, 1989-1996.

Griffiths, G., Knapp, F. F., Jr., Callahan, A. P., Chang, Z., Jones, A. L., Ostella, F., Hansen, H. J. and Goldenberg, D. M. (1991a) 'The Use of Carrier-Free Re-188 from an InHouse W-188/Re-188 Generator for Preparation of Re-188-Labeled Monoclonal Antibodies', J. Nucl. Med., in press (abstract).

Griffiths, G. L., Knapp, F. F., Jr., Callahan, A. P., Chang, C.-H., Hansen, H. J., and Goldenberg, D. M. (1991b) 'Direct Radiolabeling of Monoclonal Antibodies with Generator-Produced Rhenium-188 for Radioimmunotherapy,' Cancer Research, submitted. 
Guillaume. M., Brihaye, C., Redote, R., Zicot, M. and Knapp, F. F., Jr. (1988) 'Iridium-191m: A New Radiotracer for Arterioscintigraphy,' J. Nucl. Med. 29, 841 (abstract),

Guillaume, M., and Brihaye, C. (1987) 'Generators of Ultra-short Lived Radionuclides for Routine Clinical Applications,' Radiochimica Acta 41, 119-130.

Guillaume, M., and Brihaye, C. (1986) 'Generators for Short-lived Gamma and Positron Emitting Radionuclides: Current Status and Prospects,' Nucl. Med. Biol. 13, 89-100.

Hayes, R. L. and Rafter, J. J. (1965) 'Rhenium-188 as a Possible Diagnostic Agent,' In, Research Report, Medical Division, Oak Ridge Associated Universities, ORAU 101, 74-77.

Hayes, R. L. and Rafter, J. J., (1966) 'Rhenium-188 as a Possible Diagnostic Agent,' J. Nucl. Med. 7, 797 (abstract).

Hellman, C., Zafrir, N., Shimoni, A., Issacher, D., Trumper, J., Abrashkin, S., and Lubin, E. (1989) 'Evaluation of Ventricular Function with First-Pass Iridium-191m Radionuclide Angiography,' J. Nucl. Med. 30, 450-457.

Issachar, D., Abrashkin, S., Weiniger, J., Zemach, D., Lubin, E., Hellman, C., and Trumper, D. (1989) 'Osmium-191//ridium-191m Generator Based on Silica Gel Impregnated with Tridodecylmethylammonium Chloride,' J. Nucl. Med. 30, 538-541.

Kariemo, K. J. A., Kestila, M. S., Korhola, O. A., Hiltunen, J. V., Svahn, R. I., Knapp, F. F., Jr. and Brihaye, C. (1990) 'Determination of Kidney Perfusion Using Ultra ShortLived Iridum-191m,' Eur. J. Nucl. Med. 16, 542 (abstract).

Knapp, F. F., Jr., and Butler, T. A. (1984) 'New Systerns for Nuclear Medicine Applications,' Radionuclide Generators, ACS Sympsoium Series, No. 241, January 1984, American Chemical Society, Washington, D.C.

Kodina, G., Tulskaya, T., Gureev, E., Brodskaya, G., Gapurova, O. and Drosdovsky, B. (1990) 'Production and Investigation of Rhenium-188 Generator', In, Technetium and Rhenium in Chemistry and Nuclear Medicine 3, M. Nicolini and G. Bandoli, editors, Corina International, 635-641.

Lacy, J. L., Verani, M. S., Ball, M. E., Boyce, T. M., Gibson, R. W., and Roberts, R. (1988a) 'First-Pass Radionuclide Angiography Using a Multiwire Gamma Camera and Tantalum-178,' J. Nucl. Med. 29, 293-301.

Lacy, J. L., Ball, M. E., Verani, M. S., Wiles, H. B., Babich, J. W., LeBlanc, A D. Stabin, M., Bolomey, L., and Roberts, R. (1988b) 'An Improved Tungsten-178/Tantalum-178 Generator System for High Volume Clinical Applications,' J. Nucl. Med. 29, 15261538.

Lambrecht, R. iM. (1984) 'Radionuclide Generators,' Radiochimica Acta 34, 9-24.

Lebowitz, E., and Richards, P. (1974) 'Radionuclide Generator Systems,' In, Seminars in Nuclear Medicine 4, 257-268.

Lewis, R. E. and Eldridge, J. S. (1966) 'Production of 70-Day Tungsten-188 and Development of the 17 Hour Rhenium-188 Radioisotope Generator,' J. Nucl. Med. 7, 804-805 (abstract).

Lisic, E., Mirzadeh, S., Callahan, A. P., and Knapp, F. F., Jr. (1991) 'A New Tandem Generator/Ion Exchange System Providing Carrier-Free Rhenium-188Perrhenic Acid for Antibody Labeling,' submined, for 38th Annual Meeting of the Society of Nuclear Medicine, Cincinnati, Ohic, June 11-14, 1991. 
Mather, S. J. and Ellsion, D. (1990) 'Reduction Mediated Techentium-99m Labeling of Monoclonal Antibodies,' J. Nucl. Med. 31, 692-697.

Mathias, C. J., Welch, M. J., Green, M. A., Perry, D. J., McGuire, A. H., Zhu, X. and Connett, J. M. (1990) 'Copper PTSM Measures Tumor Blood Flow Too,' J. Nucl. Med. 31, 909 (abstract).

Minkel, D. T., Saryan, L. A. and Petering, D. H. (1978) 'Structure-Function Correlations in the Reaction of bis(thiosemicarbazonato)copper(II) Complexes with Ehrlich Ascites Tumor Cells,' Cancer Res. 38, 124-129.

Mirzadeh, S., Callahan, A. P., and Knapp, F. F., Jr. (1991) 'Iridium-194 - A New Candidate for Radioimmunotherapy (RAIT) from an Osmium-194/Iridium-194 Generator System,' submitted for 38th Annual Meeting of the Society of Nuclear Medicine, Cincinnati, Ohio, June 11-14, 1991, J. Nucl. Med., in press.

Nierinckx, R. D. (1977) 'Excitation Function for the ${ }^{62}$ Zn Bleomycin,' Int. J. Appl. Rad. Isot. $28,808-809$.

Order, S. E., Klein, J. L., Leichner, P. K., Frinke, J., Lollo, C. and Carlo, J. (1986) 'Yttrium90 Antiferritin. A New Therapeutic Radiolabeled Antibody,' Int. J. Radiat. Oncol. Biol. Phys. 12, 227-281.

Packard A. B., Treves S., and O'Brien G. M. (1987) 'An Osmium-191/-Iridium-191m Generator Using An Oxalate Osmate Parent Complex,' J. Nucl. Med., 28, 1571-1576.

Panek, K J., Lindmeyer, J. and ven der Vlugt, H. C. (1984) 'A New Generator for Production of Short-Lived Au-195m Radioisotope', In, Radionuclide Generators New Systems for Nuclear Medicine Applications, F. F. Knapp, Jr. and T. A. Butler, editors, ACS Symposium Series, No. 242, ACS, Washington, D. C., pp. 3-22.

Petering, D. II (1980) 'Carcinostatic Copper Complexes', In: Sigel, H., editor, Metal Ions in Biological Stems, New York, Marcel Dekker, pp. 197-229.

Ramamoorthy, N., Pao, P. J., and Watson, J. A. (1981) 'Preparation of a ${ }^{62} \mathrm{Zn}-{ }^{62} \mathrm{Cu}$ Generator and of ${ }^{61} \mathrm{Cu}$ Following Alpha Particle Irradiation of a Nickel Target?'

Reske, S. N., Knapp, F. F., Jr., Knoop, R. and Winkler, C. (1986) 'Fist Pass Ventikulographie mit dem Ultrakurzlebigen Radionuklid Iridium-191 m', Proceedings, European Nuclear Medicine Congress, Gosalr, Germany, Sept. 2-5, 1986 (abstract P A113).

Riley, R. J., and Tilbury, R. S. (1981) 'Production of Zinc-62 by Helium-3 Bombardment of Nickel,' Int. J. Appl. Rad. Isot. 32, 60-61.

Robinson, G. D., Jr., and Lee, A. W. (1976) 'A Short-lived Generator Produced, Positron Emitting Radionuclide for Radiopharmaceuticals,' J. Nucl. Med. 17, 559.

Robinson, G. D., Jr., Zielinsky, F. W., and Lee, A. W. (1980) 'The Zinc-62/Copper-62 Generator. A Convenient Source of Copper-62 for Radiopharmaceuticals,' Int. J. Appl. Raj. Isot. 31, 111-116.

Schelbert, H. R., Neely, J. R., Philips, M. E., and Heiss, H. W. (eds.) (1987) 'Advances in Clinical Cardiology,' Vol. III, Publisher: Foundation for Advances in Clinical Medicine, Inc., Mahwah, New Jersey.

Sharkey, R. M., Kaltovich, F. A., Shih, L. B., Fand, I., Govelitz, G. and Goldenberg, D. M. (1988) 'Radioimmunotherapy of Human Colonic Cancer Xenografts with ${ }^{90}$ Y-Labeled Monoclonal Antibodies to Carcinoembryonic Antigen', Cancer Res. 48, 3270-3275. 
'Single-Photon Ultrashort-Lived Radionuclides', P. Paras and $J$ W. Thiessen, editors, Proceedings of the Symposium held in Washington, D. C., May 9-10, 1983, published by the Office of Scientific and Technical Information, U.S. Department of Energy, CONF-830504, 1985.

Sledge, C. B., Zuckerman, J. D., Zalutsky, M. R., Atcher, R. W., Shortkroff, S. A, Lionberger, D. R., Rose, H. A. Hurson, B. J., Lankenner, P. A., Jr., Anderson, R. J. and Bloomer, W. A. (1986) 'Treatment of Rheumatoid Synovitis of the Knee with Intraarticular Injection of Dysprosium-165-Ferric Hydroxide Macroaggregates,' Arthritic and Rheumatism 29, 153-159.

Spooren, P. F. M. J., Rasker, J. J. and Arens, R. P. J. H. (1985) 'Synovectomy of the Knee with Yttrium-90,' Eur. J. Nucl. Med. 10, 441-445.

Stang, L. (1969) 'Radionuclide Generators: Past, Present, and Future,' Brookhaven National Laboratory Monograph (BNL 50186, T-541).

Thakur, M. L., and Nunn, A. D. (1969) 'Preparation of Carrier-Free Zinc-62 for Medical Use,' 2, 301-305.

Tilyou, S. A, (1990a) 'DOE Nuclear Medicine Program - Energy Agency Examines Radioisotope Needs in preparation for the Future', In, Newsline, J. Nucl. Med. 31, 13A-19A

Tilyou, S. A. (1990b) 'Radioimmunoconjugates - Targeting Disease for Diagnosis and Treatment,' In, Newsline, J. Nucl. Med. 31, 15A-30A.

Venkatesan, P. P., Shortkroff, S., Zalutsky, M. R. and Sledge, C. B. (1990) Nucl. Med. Biol. $17,357-362$.

Volkert, W. A. Goeckeler, W. F., Ehrhardt, G. J., and Ketring, A. R. (1991) 'Therapeutic Radionuclides: Production and Decay Property Considerations,' J. Nucl. Med. 32, 174 185.

Yano, Y. (1978) 'Radionuclide Generators: Current and Future Applications in Nuclear Medicine,' In, Radiopharmaceuticals, G. Subramanian, B. A. Rhodes, J. F. Cooper, and V. J. Sood, editors, Society of Nuclear Medicine, 236-245.

Yano, Y., and Budinger, T. F. (1977) 'Cyclotron Produced Zn-62: Its Possible Use in Prostrate and Pancreas Scanning as a Zn-62 Amino Acid Chelate,' J. Nucl. Med. 18, 815-821.

'Radiopharmaceuticals from Generator-Produced Radionuclides,' Panel Proceedings (STIPUB/294), from IAEA Meeting organized in Vienna, Austria, May 11-15, 1970. 
Table 1. Examples of Radionuclide Generator Systems Which Provide Ultra Short-Lived Daughters for First Pass Studies

\begin{tabular}{|c|c|c|c|c|c|}
\hline \multicolumn{3}{|c|}{ Parent } & \multicolumn{3}{|c|}{ Daughter } \\
\hline Isotope & Half-Life & Production Mode & Isotope & Half-Life & $\begin{array}{l}\text { Principal Energy, keV } \\
\text { (Abundance) }\end{array}$ \\
\hline${ }^{191} \mathrm{Os}$ & $15.4 \mathrm{~d}$ & ${ }^{190} \mathrm{Os}(\mathrm{n}, \gamma){ }^{191} \mathrm{Os}$ & ${ }^{191 \mathrm{~m}} \mathrm{Ir}$ & $4.9 \mathrm{~s}$ & $129(25 \%)$ \\
\hline${ }^{195 m} \mathrm{Hg}$ & $41.0 \mathrm{~h}$ & ${ }^{197} \mathrm{Au}(\mathrm{p}, 3 \mathrm{n}){ }^{195 \mathrm{~m}} \mathrm{Hg}$ & ${ }^{195 m} \mathrm{Au}$ & $30.6 \mathrm{~s}$ & $262(67 \%)$ \\
\hline${ }^{81} \mathrm{Rb}$ & $4.58 \mathrm{~h}$ & ${ }^{82} \mathrm{Kr}(p, 2 n){ }^{81} \mathrm{Rb}$ & ${ }^{81 \mathrm{~m}} \mathrm{Kr}$ & $13.0 \mathrm{~s}$ & $190(66 \%)$ \\
\hline${ }^{178} \mathrm{~W}$ & $21.5 \mathrm{~d}$ & $\left.{ }^{181} \mathrm{Ta}(p, 4 n)\right)^{178} \mathrm{~W}$ & ${ }^{178} \mathrm{Ta}$ & $9.3 \mathrm{~m}$ & $55-65(67 \%)$ \\
\hline
\end{tabular}


Table 2. Examples of Radionuclide Generator Systems Which Provide Positron-Emitting Radionuclide Daughter Radioisotopes

\begin{tabular}{|c|c|c|c|c|c|}
\hline \multicolumn{3}{|c|}{ Parent } & \multicolumn{3}{|c|}{ Daughter } \\
\hline Isotope & Half-Life & Production Mode & Isotope & Half-Life & $\begin{array}{c}\text { Principal Energy, keV } \\
\text { (Abundance) }\end{array}$ \\
\hline${ }^{82} \mathrm{Sr}$ & $25 \mathrm{~d}$ & ${ }^{85} \mathrm{Rb}(\mathrm{p}, 4 \mathrm{n}){ }^{82} \mathrm{Sr}$ & ${ }^{82} \mathrm{Rb}$ & $1.25 \mathrm{~min}$ & $\mathrm{~B}^{+}(511,192 \%)$ \\
\hline${ }^{62} \mathrm{Zn}$ & $9.20 \mathrm{~h}$ & ${ }^{63} \mathrm{Cu}(p, 2 \mathrm{n})^{62} \mathrm{Zn}$ & ${ }^{62} \mathrm{Cu}$ & $9.73 \mathrm{~min}$ & $\mathrm{~B}^{+}(511,194 \%)$ \\
\hline
\end{tabular}


Table 3. Examples of Radionuclide Generator Systems Which Provide Beta-Emitting Radionuclide Daughter Radionuclides for Therapeutic Applications

\section{Parent}

Isotope Half-Life Production Mode
Daughter

Isotope Half-Life Principal Energy, $\mathrm{keV}$ (Abundance)

\begin{tabular}{|c|c|c|c|c|c|}
\hline${ }^{90} \mathrm{Sr}$ & $28.8 \mathrm{y}$ & Fission & ${ }^{90} \mathrm{Y}$ & $64.1 \mathrm{~h}$ & $B_{\mathrm{av}-} 734 \mathrm{keV}(100 \%)$ \\
\hline${ }^{188} \mathrm{~W}$ & $69.4 \mathrm{~d}$ & ${ }^{186} \mathrm{~W}(\mathrm{n}, \gamma ; \mathrm{n}, \gamma){ }^{188} \mathrm{~W}$ & ${ }^{188} \mathrm{Re}$ & $16.9 \mathrm{~h}$ & $\begin{array}{r}\beta_{a v-} 764 \mathrm{keV}(71 \%) \\
\gamma 155 \mathrm{keV}(15 \%)\end{array}$ \\
\hline${ }^{194} \mathrm{Os}$ & $6.0 \mathrm{y}$ & ${ }^{192} \mathrm{Os}(\mathrm{n}, \gamma ; \mathrm{n}, \gamma){ }^{194} \mathrm{Os}$ & ${ }^{194} \mathrm{Ir}$ & $19.2 \mathrm{~h}$ & $\begin{array}{c}B_{\text {av. }} 807 \mathrm{keV}(100 \%) \\
\quad \gamma 136 \mathrm{keV}(13 \%)\end{array}$ \\
\hline
\end{tabular}


Table 4. Characteristics of Osmium-191/Iridium-191m Generator System Prototypes

\begin{tabular}{|c|c|c|c|c|c|}
\hline Adsorbent & $\begin{array}{c}\text { Osmium } \\
\text { State }\end{array}$ & $\begin{array}{l}\text { dation } \\
\text { Eluant }\end{array}$ & Characteristic & Institution & Reference \\
\hline Activated Carbon & Os(IV) & $\begin{array}{l}\text { Saline pH } 2 \\
(0.13 \mathrm{M} \text { TRIS } \\
\text { Buffer, pH 8.4) }\end{array}$ & $\begin{array}{l}\text { Consistently Long } \\
\text { Shelf-life }\end{array}$ & ORNL/Liege & $\begin{array}{l}\text { Brihaye et al., 1986a } \\
\text { 1986b }\end{array}$ \\
\hline AGMP-1 & $\mathrm{Os}(\mathrm{VI})$ & Saline $\mathrm{pH} 1$ & $\begin{array}{l}\text { Small Bolus Volume } \\
\text { for Pediatrics }\end{array}$ & $\begin{array}{l}\text { Children's Hospital } \\
\text { Boston }\end{array}$ & Packard et al.s 1987 \\
\hline $\begin{array}{l}\text { Tridodecylmethyl- } \\
\text { Ammonium Chloride } \\
\text { Silica Gel }\end{array}$ & $e^{O s(I V)}$ & $\begin{array}{l}\text { Saline, pH } 1 \\
\text { (1 M Succinate } \\
\text { Buffer, pH 9) }\end{array}$ & $\begin{array}{l}\text { Requires Charcoal } \\
\text { "Scavenger" }\end{array}$ & $\begin{array}{l}\text { Soreq Nuclear } \\
\text { Research Center }\end{array}$ & Issachar et al., 1989 \\
\hline
\end{tabular}


Table 5. Characteristics of Tungsten-188/Rhenium-188 Generator Prototypes

\begin{tabular}{lllll} 
Adsorbent & Eluant & Special Characteristic & Institution & Reference \\
\hline Alumina & Saline & Good Stability & ORNL & Callahan et al., 1989 \\
Alumina & Saline & Good Stability & $\begin{array}{c}\text { Institute of Medicine, } \\
\text { Moscow }\end{array}$ & Kodina et al., 1990 \\
Zirconium Oxide & MEK & Volatile Solvent & ORNL & Callahan et al., 1989 \\
Zirconium "Gel" & Saline & $\begin{array}{l}\text { Developed for Low Specific } \\
\text { Activity W-188 }\end{array}$ & MURR & Ehrhardt et al., 1990 \\
\hline
\end{tabular}

ORNL = Oak Ridge National Laboratory

MURR $=$ Missouri University Research Reactor 


\section{FIGURE LEGENDS}

Figure 1. Number of papers on radionsciide generator systems reported at the Society of Nuclear Medicine Meetings from 1978-1990.

Figure 2. Production and decay scheme for osmium-191 for the osmium-191/iridium-191m generator system.

Figure 3. Cyclotron production and decay scheme of tantalum-178 for the tungsten-178/tantalum-178 generator system.

Figure 4. Production and decay scheme of tungsten-188 for the tungsten-188/rhenium-188 generator cystem.

Figure 5. Production and decay scheme of osmium-194 for the osmium-194/iridium-194 generator system.

Figure 6. Production and decay scheme of zinc-62 for the zinc-62/copper-62 generator system system. 


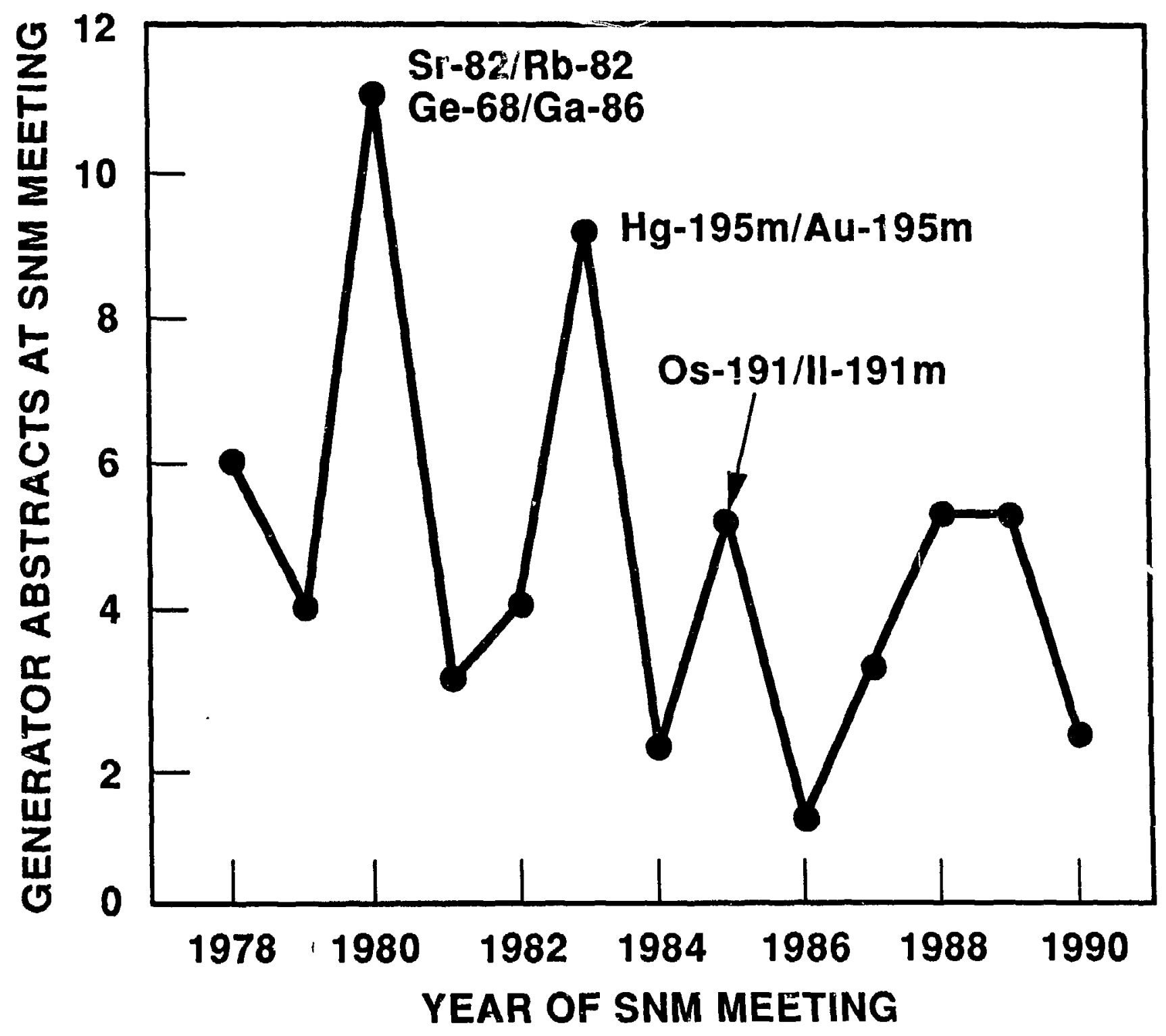




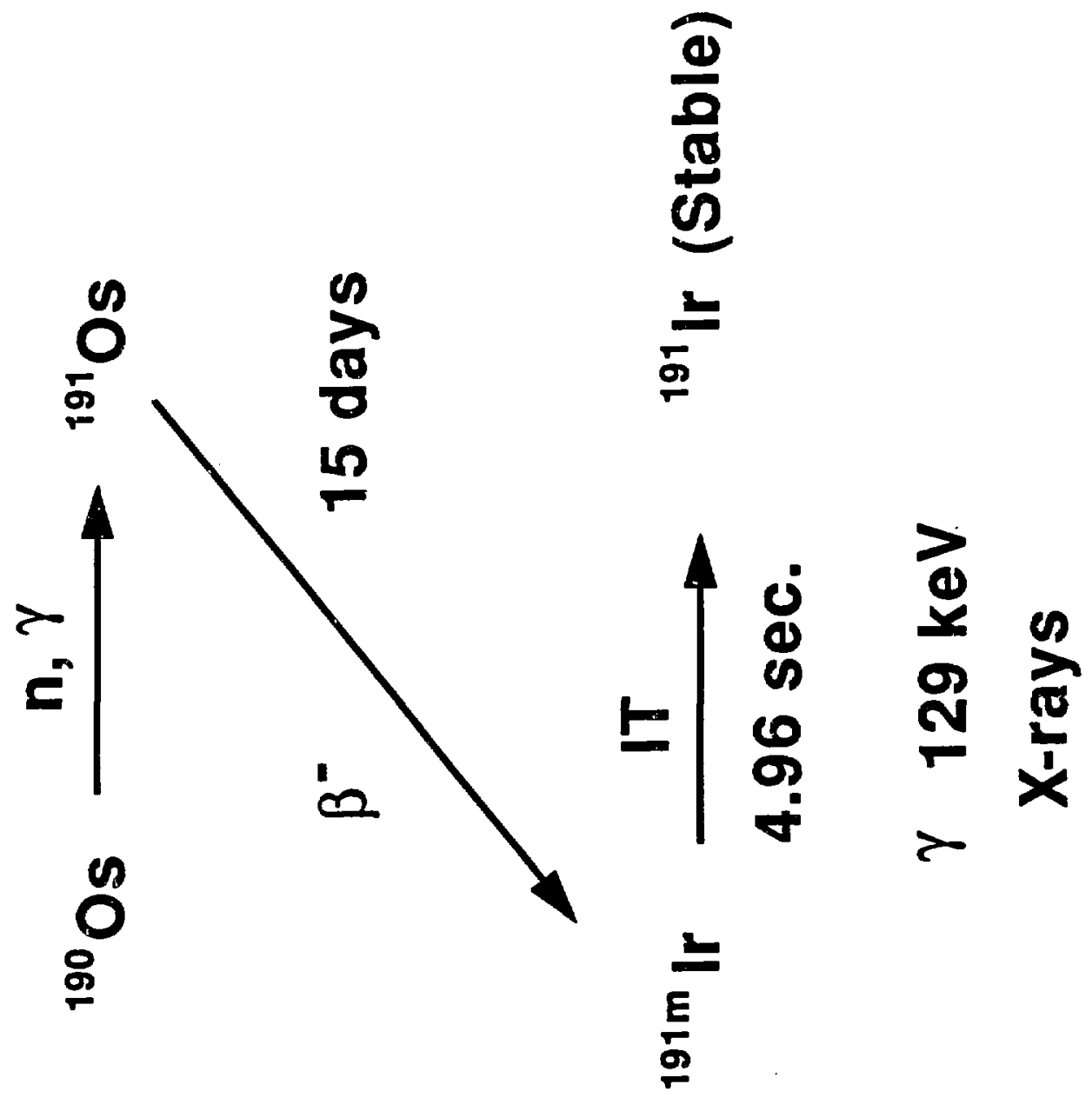




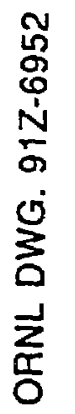

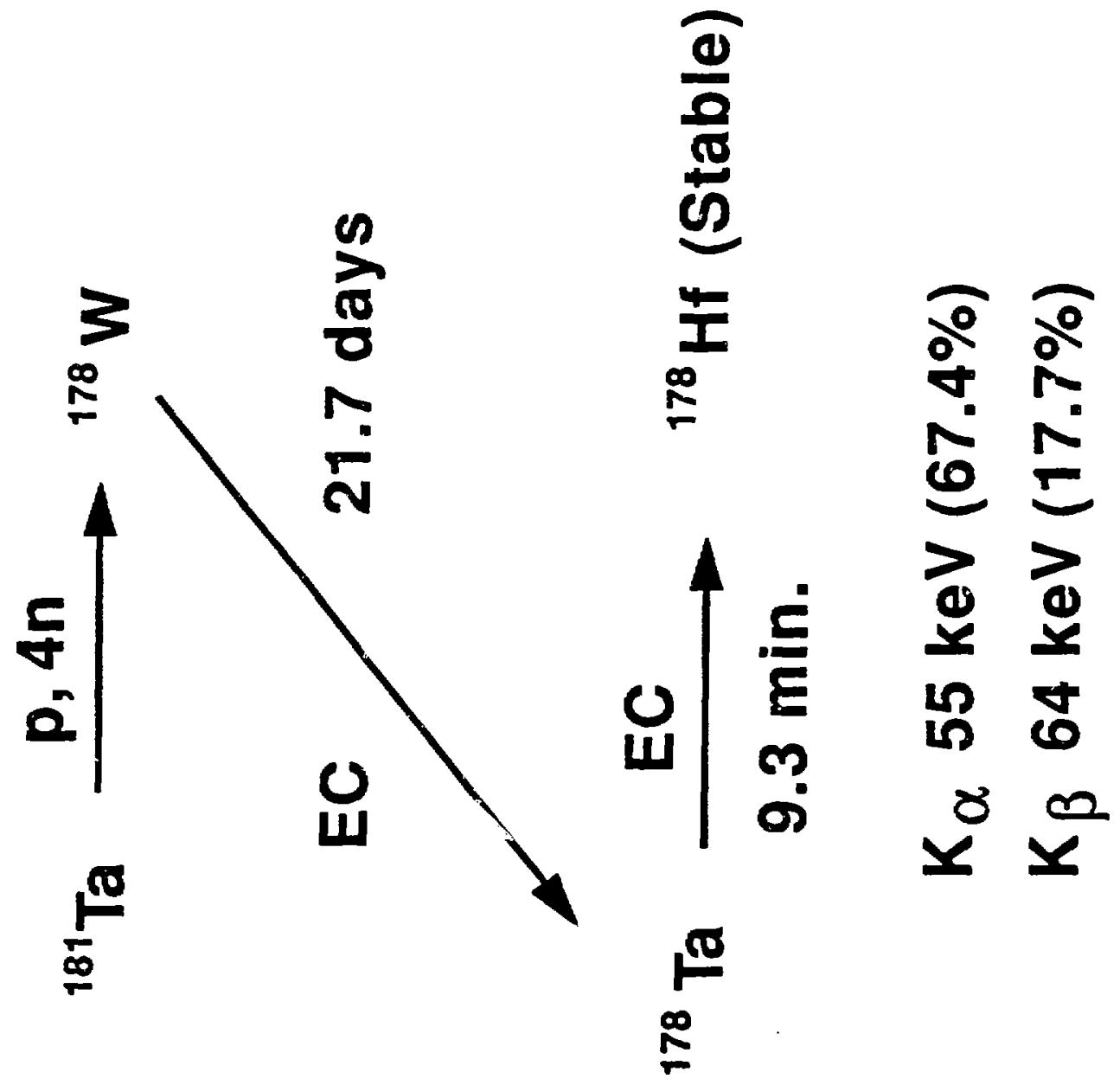




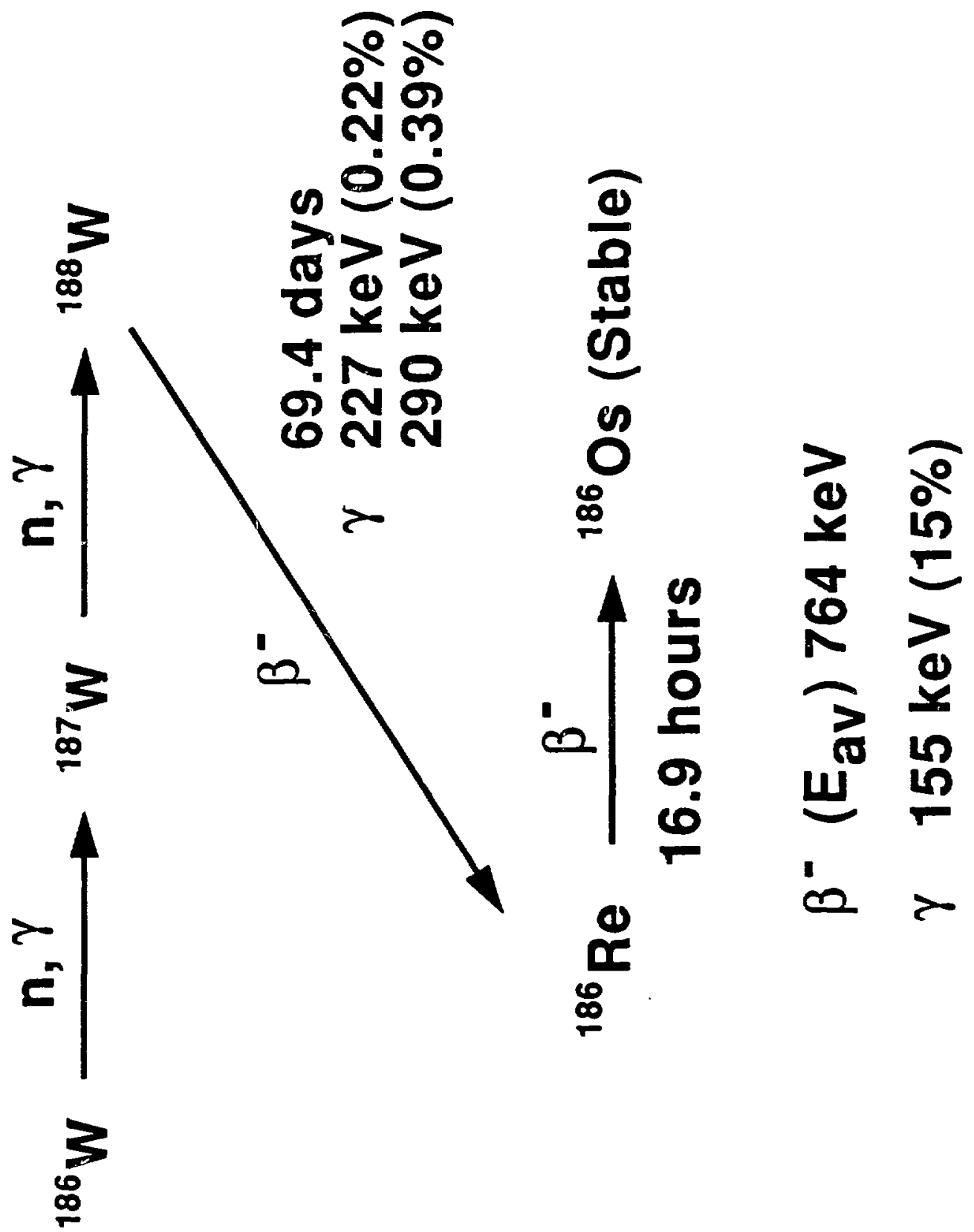




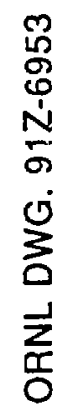

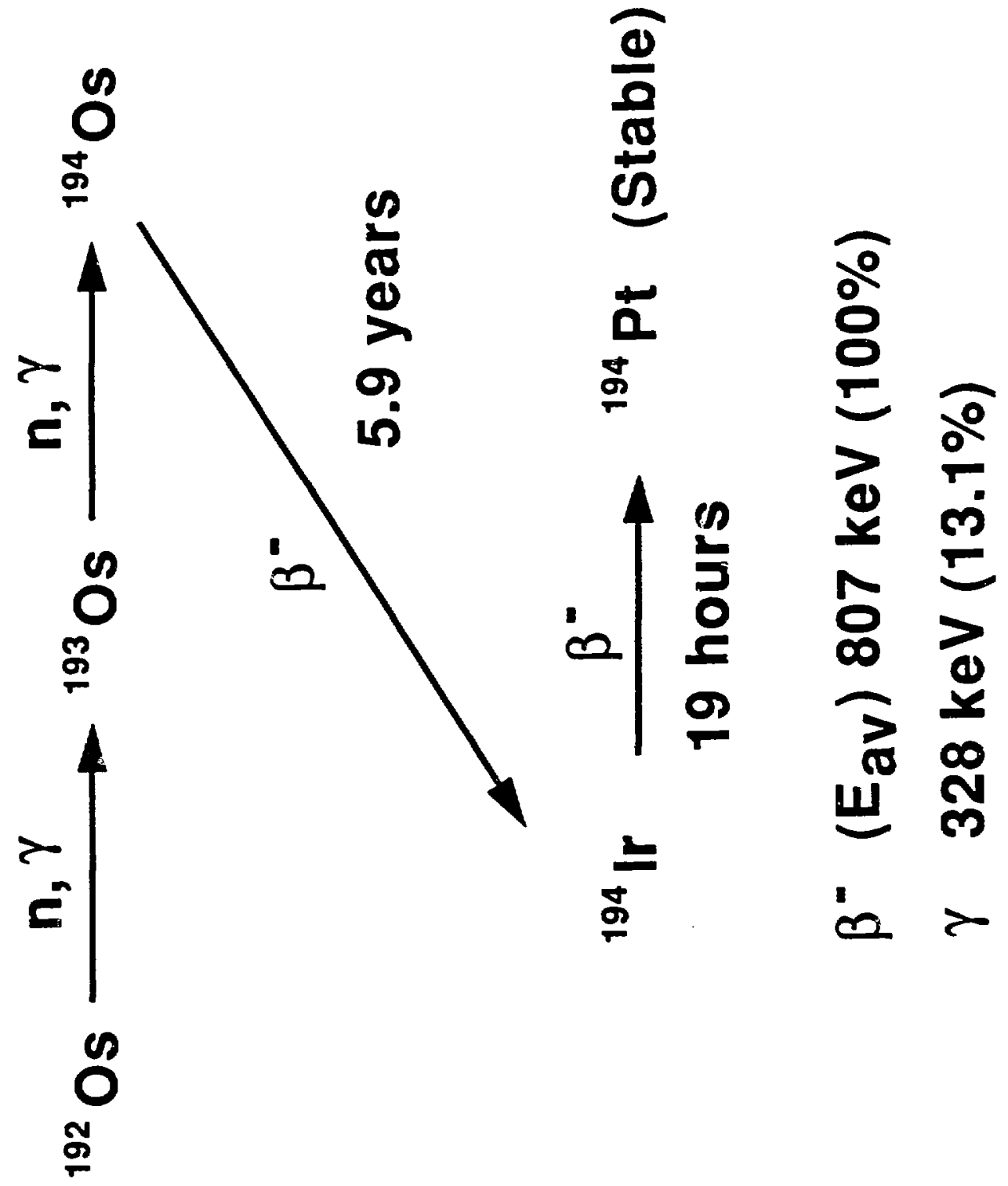




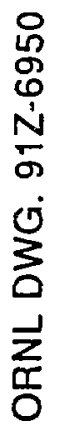

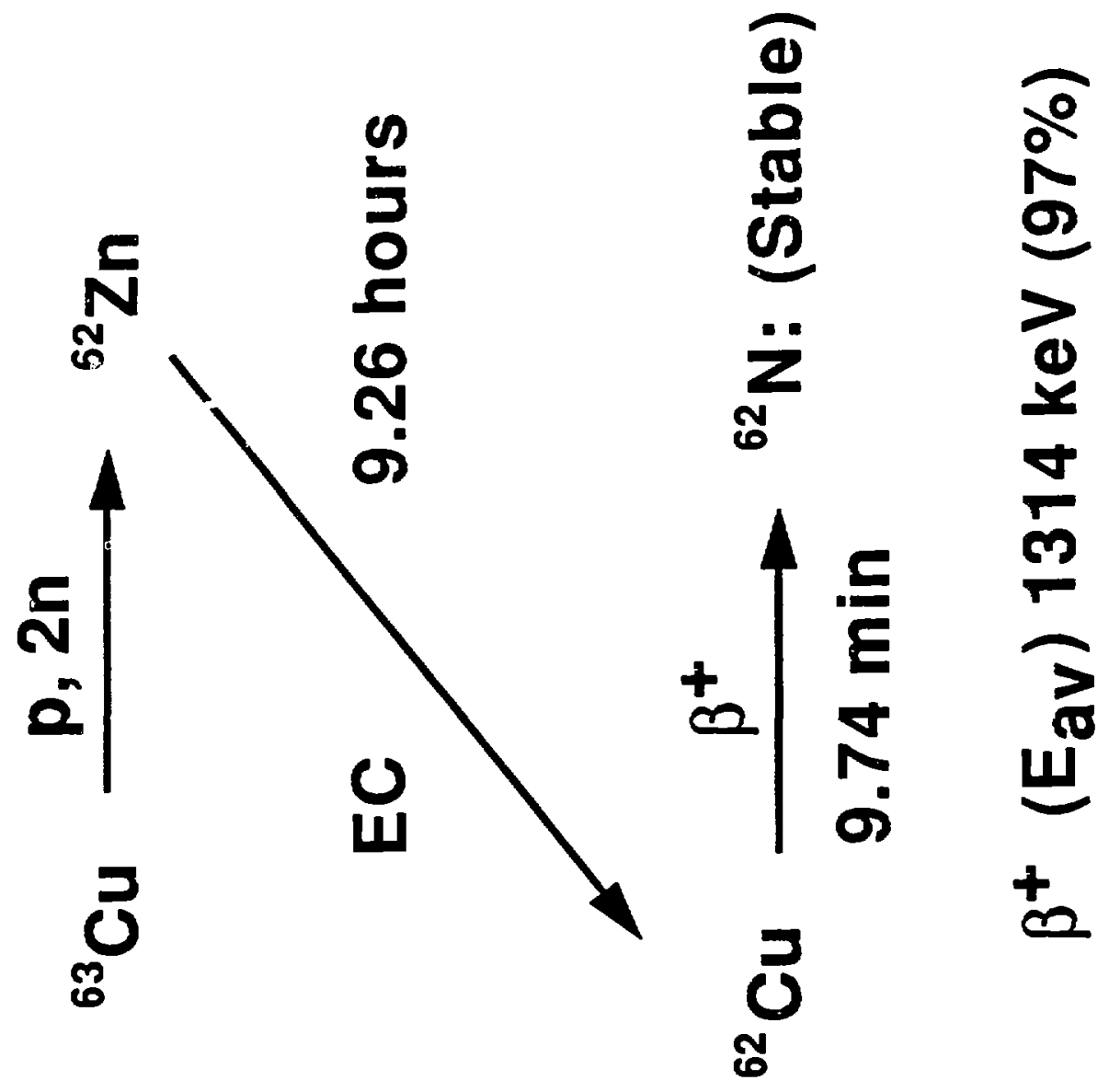

